\title{
Suicidal Behavior and Flood Effects in Bangladesh: A Two-Site Interview Study
}

This article was published in the following Dove Press journal:

Risk Management and Healthcare Policy

\author{
Mohammed A Mamun (D) ${ }^{1,2}$ \\ Mariam Binte Safiq (D) \\ Ismail Hosen (iD) I,2 \\ Firoj al Mamun (iD) ${ }^{1,2}$ \\ 'Centre for Health Innovation, \\ Networking, Training, Action and \\ Research - Bangladesh (CHINTA Research \\ Bangladesh), Dhaka, Bangladesh; \\ ${ }^{2}$ Department of Public Health and \\ Informatics, Jahangirnagar University, Savar, \\ Dhaka, Bangladesh
}

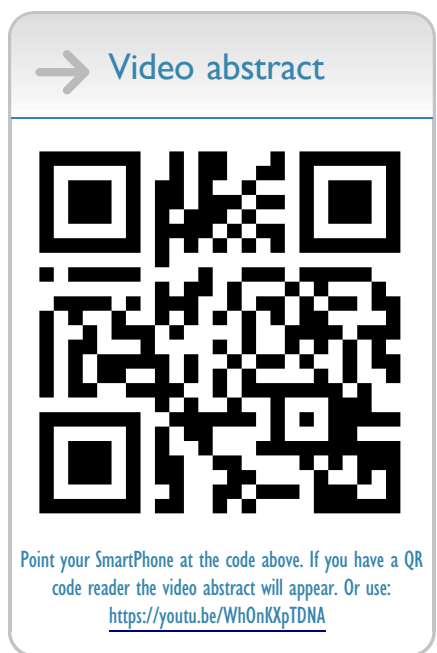

Correspondence: Mohammed A Mamun Centre for Health Innovation, Networking, Training, Action and Research - Bangladesh (CHINTA

Research Bangladesh), Dhaka, Bangladesh Tel +880 1738592653

Email mamunphi46@gmail.com
Background: Bangladeshi flood survivors are reported with such higher mental disorders that are not ever observed in any other cohorts. Although there are a few studies that assessed mental disorders, suicide or suicidal behaviors are not investigated yet. Hence, the present study for the first time investigated suicidal behaviors and its relationship with sociodemographics, flood effects and psychopathology.

Methods: A cross-sectional interview study was carried out between November and December 2019, after 4/5 months of the flood occurrence. Two completely affected villages from two districts residing in two parts of the country were randomly selected (whereas Manikganj district was less affected by the recent flood compared to Kurigram), and a total of 348 flood survivors were interviewed (45.53 \pm 14.85 years). Questions related to basic socio-demographics, flood effects, psychological impacts, and suicidal behaviors were asked in the interviews.

Results: In the total sample, $57.5 \%$ of flood survivors reported having suicidal ideation, whereas $5.7 \%$ and $2.0 \%$ madea suicide plan and suicide attempt, respectively. Within two study sites, participants belonging to Kurigram reported significantly higher suicidal ideation compared to Manikganj (84.8\% vs $\left.33.2 \%, \chi^{2}=94.475, p<0.001\right)$. Belonging to a lower-class family, having less education, and less earning members in the family, being affected severely by the flood, suffering from depression, anxiety, and PTSD, and experiencing financial threat, and economic hardship were suicidal behavior risk factors in the total sample.

Conclusion: Considering the present findings (ie, suicidality commensurately increases with flood effects), a multi-sectoral policy and its effective implementation should be adopted for alleviating the flood-related psychological burdens.

Keywords: natural disaster, flood effects, depression, PTSD, suicidal behavior, flood suicide, flood in Bangladesh

\section{Introduction}

As of geographical location, Bangladesh is highly prone to frequent and recurring natural disasters like cyclones, storm surges, floods, and riverbank erosions; most remarkably the country is affected by floods because of heavy rains and overflowing rivers. ${ }^{1,2}$ Consequently, the country has to experience cyclones or floods almost every year; that is, 75 severe cyclones and floods are reported during the last 100 years. $^{3}$ Besides, at least 1,200 kilometers of riverbank erosion occurs every year in the country, ${ }^{3}$ resulting in more flood occurrences. For instance, 21 out of a total of 64 districts in both the north-eastern and north-western parts of Bangladesh have been affected in 2019, with at least 119 deaths as of drowning, 
snake bites and lightning strikes, etc. ${ }^{4}$ More than 580,000 houses have been damaged, which leads to people taking their temporary shelter in government-supported 1,000 centers. The report says, at least 307,000 people are sheltered within 10 to 24 July 2019, which reflects the actual number would be much higher. ${ }^{4}$ The Ministry of Health and Family Welfare, Bangladesh concerned about the effects of the flood, which highlights the poor quality of life of the flood-affected people. ${ }^{5}$

Devastating natural disasters like floods have enormous economic and health-related consequences. Of the effects, although the physical impairments can be recovered over time, the economic and psychological sufferings remain as devastating factors of quality of life., ${ }^{2,6}$ For instance, Bangladesh reports a higher portion of suicide because of economic recession and crisis accounting as the second most suicide causality after emotional stress due to family conflicts. $^{7}$ And suicide is tremendously linked with the extreme mental instabilities, a common outcome of economic-related crises, ${ }^{8,9}$ accounting for almost $90 \%$ of global suicide occurrences as of these mental sufferings. ${ }^{10,11}$ Hence, available information on flood-affected peoples' mental health is urgent for considering suicide preventive and mental wellbeing initiatives. But there is a limited study assessing mental health in Bangladesh; consequently, flood-related mental health problems are subsequently ignored to be addressed. . $^{3,12,13}$

Only three available studies assessed the mental health status in the country to the authors' best knowledge. For instance, $66 \%$ of the disaster-affected people by the 1996 tornado in Tangail district are traumatized and in need of psychological help. ${ }^{13}$ Whereas $25 \%$ of the 2007 cyclone Sidr survivors experience PTSD, and $18 \%, 16 \%$ and $15 \%$ have a major depressive disorder, somatoform disorder, mixed anxiety and depression, respectively. ${ }^{13}$ A very recent study by Mamun et $\mathrm{al}^{2}$ reports $64.9 \%$ of the 2017 cyclone Mora survived women suffered from depression. Therefore, the mental health suffering figure aftermath a natural disaster is extremely higher than general people's sufferings (ie, $6.5 \%$ to $31.0 \%$ and $13.4 \%$ to $22.9 \%$ mental disorders prevalence rates are reported for Bangladeshi adults and children, respectively ${ }^{12}$ ). Hence, a larger portion of the flood survivors is being affected mentally with the mediation of disasterrelated economic crisis, which may lead them to suicide as aforementioned. But there is no estimation of flood-related suicide in the country, as the country has no suicide surveillance system or no suicide study assessing this cohort. ${ }^{3,13-15}$ Besides, the government launched a program mitigating the flood effects although, the plan lacks guidelines on mental health-care delivery, which emerges the available information to reformulate the policy, ${ }^{13}$ However, for aiming to support the situation by providing the extreme mental health related information (ie, suicidal behaviors), the present study for the first time investigates the suicidal behaviors of the Bangladeshi flood survivors.

\section{Methods}

\section{Study Sites and Population}

The present cross-sectional study was carried out within two randomly selected districts of Bangladesh (ie, Manikganj and Kurigram), these were affected during the 2019 flood. Manikganj was reported having at least 50,000 families affected by the flood, ${ }^{16}$ whereas it was 72,480 families for Kurigram. ${ }^{17}$ At least 300 houses were destroyed because of flooding in Manikganj, whereas it was more than three times higher in Kurigram (i., 1,031 houses). ${ }^{16,17}$ As no active surveillance systems focusing on the flood-related mortality in the country, no specific district-wise deaths can be reported herein. Two villages from each district (ie, belonging to Boyra union for Manikganj [less affected] and Nunkhawa Char union for Kurigram [more affected]) were randomly selected, which were completely affected by the recent flood. The study required only an adult participant from each family, and following this criteria, a total of 362 families were eligible for participating, but 348 participants were interviewed (mean age $=45.53 \pm 14.85$ years).

\section{Study Procedure}

The study was conducted by a face-to-face interview between November and December 2019, after 4/5 months of the flood occurrence. The face-to-face interviews were carried out by the local research assistants, who were trained by the research team in support of the respective Chairman(s). However, the structured questionnaire that was administered consisted of questions related to sociodemographic, flood-related events and outcomes, financial threat, economic hardship, depression, anxiety, PTSD, and suicidal behaviors. Each interview lasted around 45 minutes.

\section{Measures}

\section{Socio-Demographic Questions}

The basic socio-demographic information such as gender, age, monthly family income, number of children, 
educational qualification, earning member in family, etc., were asked in the interview. The family status (ie, less than 15-thousand BDT income was regarded as lower-class family, whereas it was 15 to 30 -thousand BDT and more than 30-thousand BDT for the middle class and higher class, respectively) was classified based on the previous Bangladeshi study recommendation on monthly family income. ${ }^{9}$ As there were only 4-participants responding to the higher class, this was amended with the middle class. Besides, having children was classified into two groups based on the perception of joint and nuclear family. ${ }^{18}$

\section{Flood-Related Questions}

Flood-related information such as events information and its consequences were also asked. There were two items on event information considering the preparedness of the flood (ie, flood prior warning, and post-flood preventive measures). Besides, several questions based on a binary response (except one item, that is, total economic loss due to the flood) were asked to measure the effects of the flood based on the previous studies. ${ }^{2,19,20}$ The effects of the flood include concerns related to any sorts of injury, loss of work, loss of a family member, etc (the full list of the exact items is presented in the Supplementary Table S1). Besides, total economic loss due to the flood considered all sorts of damage including house damage, loss of harvest and dairy cattle, damage to furniture, etc., in Bangladeshi currency (BDT) and was categorized based on the previous Bangladeshi flood study recommendation. ${ }^{2}$ Lastly, if they were aware of taking preventive measures regarding the issues such as drinking boiled water, eating safe food, avoiding insect or snake bite, etc., based on an overall binary response.

\section{Patient Health Questionnaire (PHQ-9)}

Depression was assessed by using the 9-item Patient Health Questionnaire, ${ }^{21}$ which was previously deployed in Bangladeshi sample. ${ }^{2}$ Participants were asked how often they suffered during the past two weeks by each of the nine core symptoms of depression and their responses were recorded on a 4 -point Likert scale $(0=$ not at all, $1=$ several days, $2=$ more than half of the days, $3=$ nearly every day). The scale has a score range between 0 and 27 . A score of $\geq 10$ was taken as a cutoff score for the presence of depression, which has $88 \%$ sensitivity and $88 \%$ specificity for detecting depression. ${ }^{21,22}$ In the present study, Cronbach's alpha was 0.86 .

\section{Generalized Anxiety Disorder (GAD-7)}

Anxiety was assessed by using the 7-item of Generalized Anxiety Disorder, ${ }^{23}$ which was previously deployed in Bangladeshi sample. ${ }^{24}$ Participants were asked how often they were bothered during the past two weeks by each of the seven core symptoms of generalized anxiety disorder and their responses were recorded on a 4-point Likert scale $(0=$ not at all, $1=$ several days, $2=$ more than half of the days, and 3 = nearly every day). The scale has a score range between 0 and 21 . A score of $\geq 10$ was taken as a cutoff score for the presence of anxiety, which has $89 \%$ sensitivity and $82 \%$ specificity for detecting anxiety. ${ }^{23,24}$ In the present study, Cronbach's alpha was 0.87 .

\section{Trauma Screening Questionnaire (TSQ- I0)}

PTSD related to the flood was assessed by using the 10item Trauma Screening Questionnaire. ${ }^{25}$ The TSQ is consisted of 10-item questions where reexperience consisting of 5 items (eg, "upsetting thoughts or memories about the event that have come into your mind against your will") and other 5 items (eg, "difficulty falling or staying asleep") belong to arousal based on the PTSD diagnosis criteria. Participant's response was recorded on a Binary response (Yes/No) whether they had experienced any of the following symptoms at least twice in the past week or not. Although Brewin et $\mathrm{al}^{25}$ suggested an optimal cutoff score of 6 out of a total 10 score, the present study used 7 , which was advocated as the balanced best cutoff score based on sensitivity and specificity test by Dekkers et al. ${ }^{26}$ In the present study, Cronbach's alpha was 0.80 .

\section{Financial Threat Scale (FTS-5)}

Financial threat was assessed by using 5-item of the Financial Threat Scale, ${ }^{27,28}$ which was previously deployed in Bangladeshi sample. ${ }^{8}$ Participants were asked questions such as "how uncertain do you feel?" to investigate the financial threat and their responses were recorded on a 5 -point Likert scale $(1=$ Not at all, to $5=$ extremely uncertain). The scale has a score range between 5 and 25, whereas higher scores indicate a higher financial threat. Previous studies showed higher internal consistency, $8,27,28$ which was consistent in the present sample (ie, Cronbach's alpha was 0.91).

\section{Economic Hardship Questionnaire (EHQ-6)}

Economic hardship was assessed by using the 6-item Economic Hardship Questionnaire, ${ }^{28,29}$ which was previously deployed in the Bangladeshi sample. ${ }^{8}$ Participants were asked questions such as "during the last 
few years, did your family cut back on social activities and entertainment expenses?" to investigate economic hardship, and their responses were recorded on a 4-point Likert scale ( $1=$ Never, $2=$ Seldom, $3=$ Sometimes, $4=$ Very often). The scale has a score range between 6 and 24, whereas higher scores indicate higher economic hardship. Previous studies showed higher internal consistency, ${ }^{8,28}$ which was consistent in the present sample (ie, Cronbach's alpha was 0.91).

\section{Suicidal Behaviors}

Suicidal behaviors (that is, suicidal thought, suicide plan and suicide attempt) were assessed by asking detailed questions responding on a binary option (Yes/No) following the previous studies conducted inside ${ }^{30,31}$ and outside ${ }^{32,33}$ Bangladesh. Participants were asked (i) suicidal thought: if they had thought about committing suicide aftermath of the flood, whether such thoughts were persistent up to the survey time, (ii) suicide plan: whether they had made suicide plans to kill themselves within the period, and (iii) suicide attempt: whether they had attempted for suicide within the period. ${ }^{30,32,34}$ Previously, the method was also used in the natural disaster context. ${ }^{35}$

\section{Ethical Approval}

The study protocol was initially reviewed by the Centre for Health Innovation, Networking, Training, Action, and Research - Bangladesh (CHINTA Research Bangladesh), and it was formally approved by the ethics board at the Institute of Clinical Immunology of Bangladesh (Reference number: IRBIACIB/CEC/03201925/272). Besides, the study implementation got supported by the respective union Chairman (where the two villages reside). All participants provided informed (written or verbal) consents and also, they were ensured about the confidentiality of their data. They would be able to withdraw their participation at any time during the interview session, were also informed.

\section{Statistical Analysis}

The data were entered using a Google Form, that was cleaned and prepared for final analysis by Microsoft Excel 2019. Statistical Package for Social Science (SPSS) version 22.0 was used for the formal data analysis, whereas Figures were done with Microsoft Excel 2019. The present study termed "suicidal behavior" as an outcome for bivariate and multivariate analysis, which was based on the response of suicidal ideation; ${ }^{30,33}$ exactly it was used in the natural disaster context. ${ }^{35}$ For categorical variables, frequencies, percentages, and chi-square /Fisher's Exact tests were used to see the relationship between the suicidal behavior and the studied variables, where independent sample $t$-tests were performed for continuous variables. Besides, a binary regression was performed to see the risk factor of suicidal behavior, whereas the results were interpreted with $95 \%$ confidence intervals and a $p$-value less than or equal to 0.05 as significant.

\section{Results}

\section{Distribution of Socio-Demographic and Flood-Related Variables}

Table 1 presents the socio-demographic and flood-related variables concerning study sites. In the total sample, $50.6 \%$ gender was female, $89.5 \%$ belonged to a lowerclass family, $87.5 \%$ had less than 5 children, $45.8 \%$ had no formal education, and only $4.9 \%$ had no earning members in the family. Around half of the total participants (46.4\%) reported having been severely affected by the flood, although the rate was approximately three times higher among the participants from Kurigram compared to Manikganj $\left(70.7 \%\right.$ vs $\left.25.0 \%, \chi^{2}=91.956, p<0.001\right)$. Similarly, about $63 \%$ of the total participants were found to not get a warning before flood incidence and not take preventive measures after the incidence. However, a larger portion of the participants belonging to Kurigram did not take any preventive measures in respect to hygienic food and water, avoid insect and snake bites, etc $(73.5 \%$ vs $\left.54.1 \%, \chi^{2}=13.844, p<0.001\right)($ Table 1$)$.

\section{Distribution of Suicidal Behavior Across Study Sites}

Figures present the suicidal behaviors across total and two study sites. In the total sample, about $57.5 \%$ of the respondents $(n=200)$ reported having any types of suicidal thought or ideation, where $5.7 \%(\mathrm{n}=20)$ and $2.0 \%(\mathrm{n}=7)$ had made a suicide plan and suicide attempt, respectively. Although three types of suicidal behavior were higher among the participants from Kurigram compared to Manikganj, it was only significant in respect to suicidal ideation $\left(84.8 \%\right.$ vs $33.2 \%, \chi^{2}=94.475, p<0.001$; but $\chi^{2}=$ $1.411, p=0.235$ and $\chi^{2}=1.693, p=0.193$ for suicide plan and suicide attempt, respectively) (Figure 1). 
Table I Distribution of the Studied Variables Across the Study Site

\begin{tabular}{|c|c|c|c|c|c|}
\hline Variables & Total (348; 100\%) & Manikganj (184; 52.9\%) & Kurigram $(164 ; 47.9 \%)$ & $\chi^{2}$ Test Value & $p$-value \\
\hline \multicolumn{6}{|l|}{ Gender } \\
\hline Female & $176(50.6 \%)$ & $107(58.2 \%)$ & $69(42.1 \%)$ & \multirow[t]{2}{*}{8.968} & \multirow[t]{2}{*}{0.003} \\
\hline Male & $172(49.4 \%)$ & $77(41.8 \%)$ & $95(57.9 \%)$ & & \\
\hline \multicolumn{6}{|l|}{ Family status } \\
\hline Lower class & $306(89.5 \%)$ & $158(87.8 \%)$ & 148 (91.4\%) & \multirow[t]{2}{*}{1.160} & \multirow[t]{2}{*}{0.281} \\
\hline Middle class & $36(10.5 \%)$ & $22(12.2 \%)$ & $14(8.6 \%)$ & & \\
\hline \multicolumn{6}{|c|}{ Having number of total children } \\
\hline I to 4 & $300(87.5 \%)$ & $168(92.8 \%)$ & $132(81.5 \%)$ & \multirow[t]{2}{*}{10.019} & \multirow[t]{2}{*}{0.002} \\
\hline More than 4 & $43(12.5 \%)$ & $13(7.2 \%)$ & $30(18.5 \%)$ & & \\
\hline \multicolumn{6}{|c|}{ Educational status } \\
\hline No education & 159 (45.8\%) & $69(37.7 \%)$ & $90(54.9 \%)$ & \multirow[t]{3}{*}{14.039} & \multirow[t]{3}{*}{0.001} \\
\hline Primary & $146(42.1 \%)$ & $83(45.4 \%)$ & $63(38.4 \%)$ & & \\
\hline Secondary & $42(12.1 \%)$ & $31(16.9 \%)$ & II (6.7\%) & & \\
\hline \multicolumn{6}{|c|}{ Having number of earning members in the family } \\
\hline None & $17(4.9 \%)$ & $7(3.8 \%)$ & $10(6.1 \%)$ & \multirow[t]{3}{*}{15.509} & \multirow[t]{3}{*}{$<0.001$} \\
\hline One & $252(72.4 \%)$ & $120(65.2 \%)$ & $132(80.5 \%)$ & & \\
\hline More than one & $79(22.7 \%)$ & 57 (31.0\%) & $22(13.4 \%)$ & & \\
\hline \multicolumn{6}{|c|}{ Getting flood warning prior its incidence } \\
\hline No & $218(62.8 \%)$ & $110(59.8 \%)$ & $108(66.3 \%)$ & \multirow[t]{2}{*}{1.552} & \multirow[t]{2}{*}{0.213} \\
\hline Yes & $129(37.2 \%)$ & $74(40.2 \%)$ & $55(33.7 \%)$ & & \\
\hline \multicolumn{6}{|c|}{ Preventive measures taken } \\
\hline No & $218(63.2 \%)$ & $99(54.1 \%)$ & $119(73.5 \%)$ & \multirow[t]{2}{*}{13.844} & \multirow[t]{2}{*}{$<0.001$} \\
\hline Yes & $127(36.8 \%)$ & $84(45.9 \%)$ & $43(26.5 \%)$ & & \\
\hline \multicolumn{6}{|l|}{ Effects of flood } \\
\hline Severe effect & $162(46.4 \%)$ & $46(25.0 \%)$ & $116(70.7 \%)$ & \multirow[t]{3}{*}{91.956} & \multirow[t]{3}{*}{$<0.001$} \\
\hline Moderate effect & $147(42.2 \%)$ & $100(54.3 \%)$ & $47(28.7 \%)$ & & \\
\hline Lower effect & $39(11.2 \%)$ & $38(20.7 \%)$ & $\mathrm{I}(0.6 \%)$ & & \\
\hline \multicolumn{6}{|l|}{ Depression } \\
\hline No & 121 (34.8\%) & 87 (47.3\%) & 34 (20.7\%) & \multirow[t]{2}{*}{26.952} & \multirow[t]{2}{*}{$<0.001$} \\
\hline Yes & 227 (65.2\%) & 97 (52.7\%) & 130 (79.3\%) & & \\
\hline \multicolumn{6}{|l|}{ Anxiety } \\
\hline No & 194 (55.7\%) & 114 (62.0\%) & 80 (48.8\%) & 6.102 & 0.014 \\
\hline Yes & 154 (44.3\%) & 70 (38\%) & 84 (5।.2\%) & & \\
\hline PTSD & & & & & \\
\hline No & $60(17.2 \%)$ & 46 (25.0\%) & 14 (8.5\%) & 16.472 & $<0.001$ \\
\hline Yes & $288(82.8 \%)$ & $138(75.0 \%)$ & 150 (91.5\%) & & \\
\hline
\end{tabular}



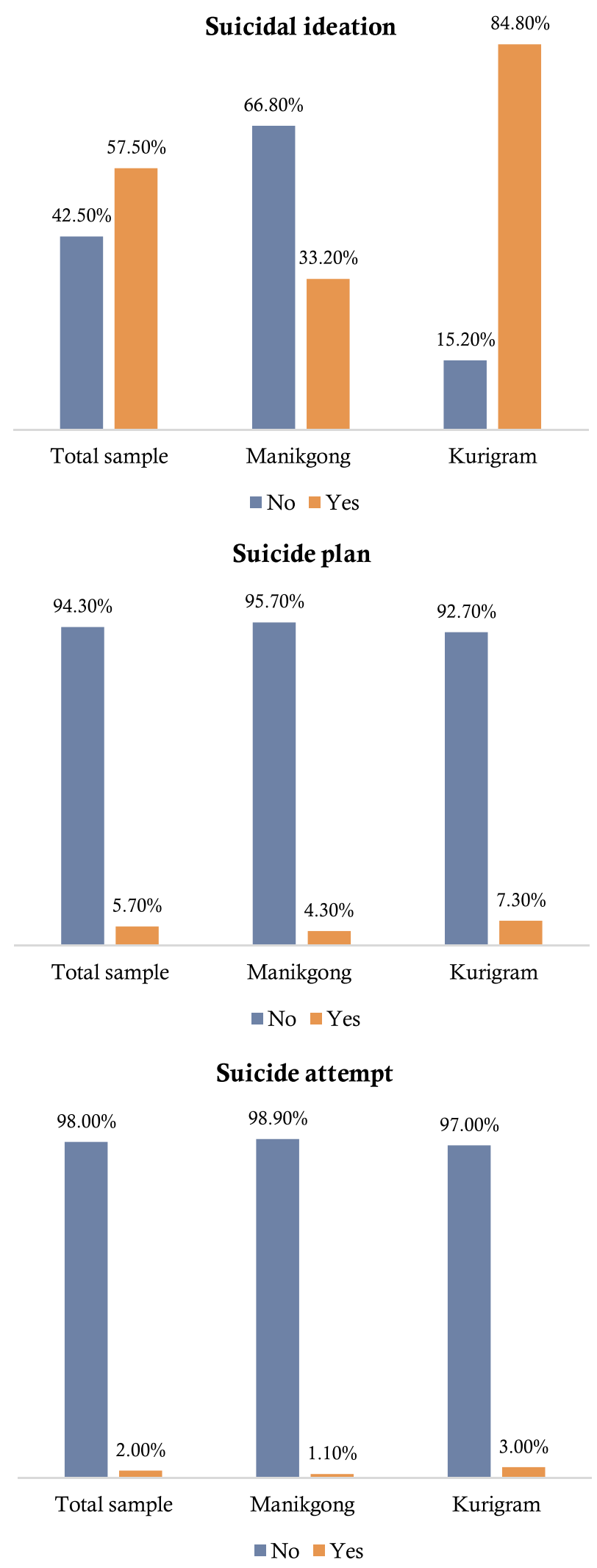

Figure I Distribution of suicidal behavior across the study site.

\section{Distribution of Suicidal Behavior with Studied Variables}

Suicidal behavior was significantly higher among the participants with lower-class family status compared to middle class belonging to total sample $\left(59.5 \%\right.$ vs $41.7 \%, \chi^{2}=$ 4.184, $p=0.041)$ and Kurigram $\left(86.5 \%\right.$ vs $64.3 \%, \chi^{2}=$ $4.830, p=0.028)$. Similarly, participants having less education and less earning members in the family were more prone to suicidal behavior in the total sample. Considering the flood effects in the total sample, $71.0 \%$ of the survivors with severe flood effects had suicidal behavior, whereas the rate was commensurately decreased with fewer flood effects $\left(\chi^{2}=30.778, p<0.001\right)$. About $69.2 \%$ of the depressed participants from total sample were suicideprone $\left(35.5 \%\right.$ non-depressed participants, $\chi^{2}=36.513$, $p<0.001$ ), which was significant in only Manikganj $\left(45.4 \%\right.$ vs $\left.19.5 \%, \chi^{2}=13.798, p<0.001\right)$. Similarly, anxiety and PTSD suffering were also reported to increase the suicidal behavior rate in the total sample and Manikganj (Table 2).

\section{Distribution of Suicidal Behavior with Continuous Variables}

Table 3 represents the mean differences of continuous variables with suicidal behavior. The mean score of financial threat was reported $18.689( \pm 4.299)$ in total sample, which significantly increased with the presence of suicidal behavior across either total sample (19.85 \pm 4.34 vs 17.11 $\pm 3.71, \mathrm{t}=6.185, p<0.001)$, Manikganj $(19.49 \pm 3.41$ vs $17.15 \pm 3.97, \mathrm{t}=3.934, p<0.001)$ or Kurigram $(20.01 \pm$ 4.69 vs $16.92 \pm 2.02, \mathrm{t}=3.233, p<0.001)$. Similarly, higher economic hardship was associated with suicidal behavior in the three samples $(\mathrm{t}=-6.979, p<0.001 ; \mathrm{t}=4.131$, $p<0.001$; and $\mathrm{t}=3.312, p<0.001$ for the total sample, Manikganj, and Kurigram, respectively) (Table 3).

\section{Risk Factors of Suicidal Behavior}

Table 4 shows the suicidal behavior risk factors across total sample and study sites. In total sample, belonging to lower class family $(\mathrm{OR}=2.055, \mathrm{CI}=1.020-4.141 ; p=$ $0.044)$, having less education $(\mathrm{OR}=3.390, \mathrm{CI}=1.654-$ 6.948 and $\mathrm{OR}=2.867, \mathrm{CI}=1.394-5.897 ; p=0.004$ for no formal education and primary education, respectively, compared to secondary education), having less earning 


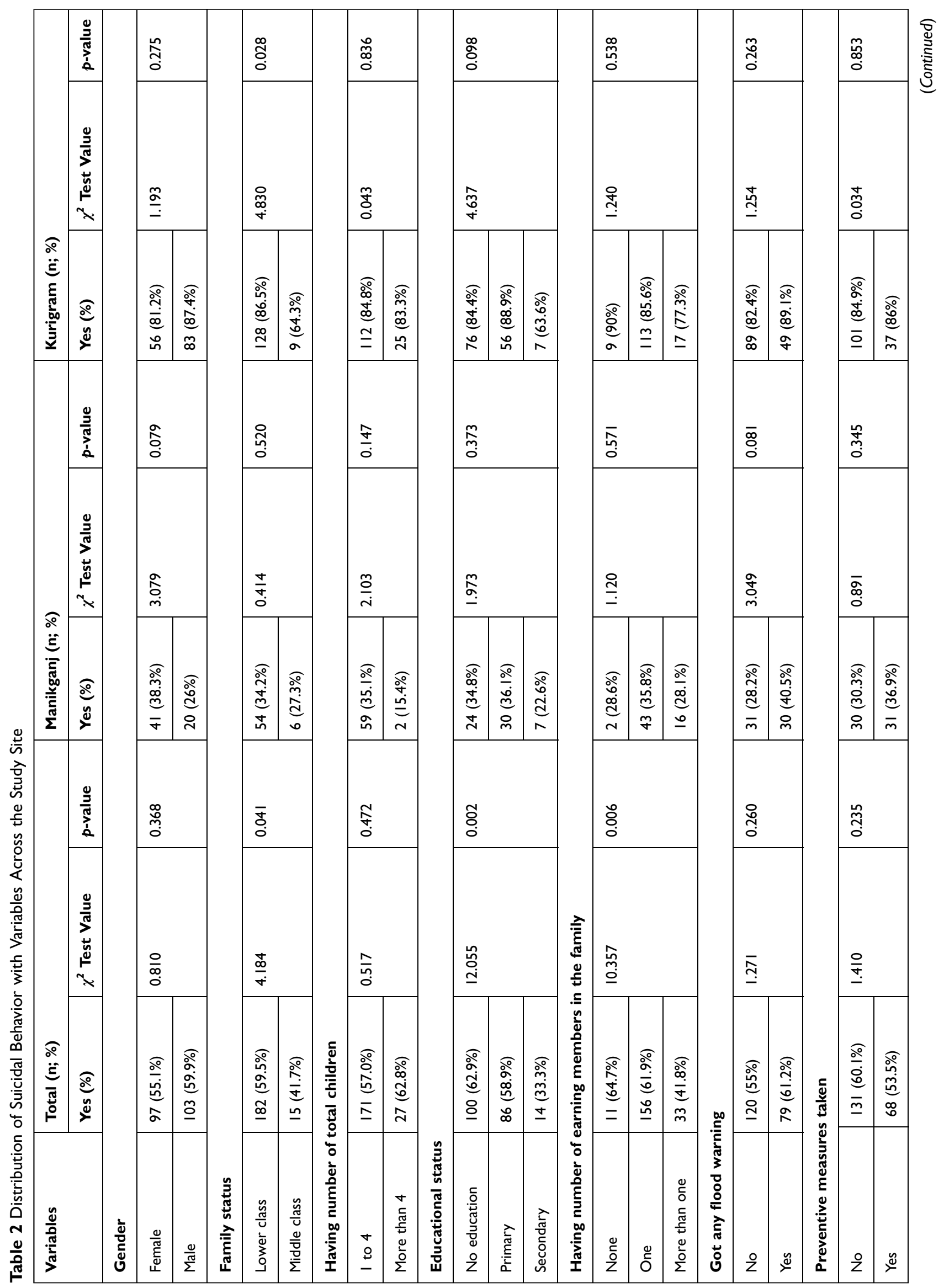




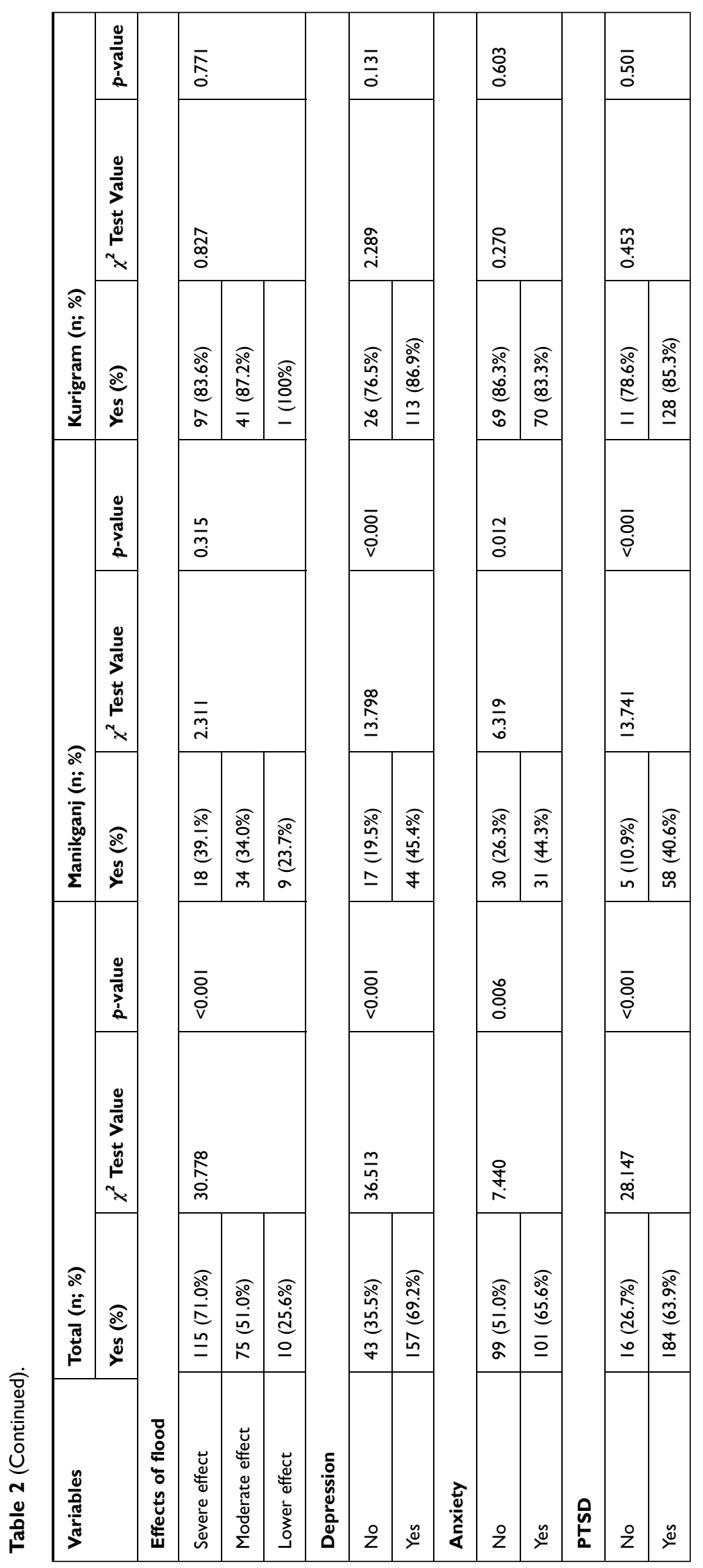




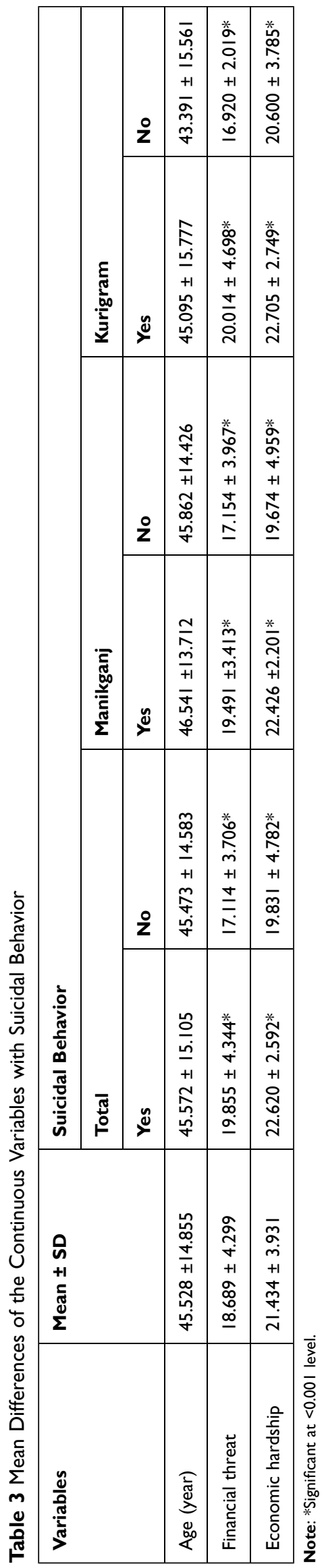

member $(\mathrm{OR}=2.556, \mathrm{CI}=0.859-7.605$ and $\mathrm{OR}=2.265$, $\mathrm{CI}=1.354-3.789 ; p=0.006$ for no earning member and one member respectively, compared to more members), being affected heavily by the flood $(\mathrm{OR}=7.096$, $\mathrm{CI}=$ $3.205-15.710$ and $\mathrm{OR}=3.021, \mathrm{CI}=1.374-6.644 ; p<0.001$ for severe effect and moderate effect respectively, compared to lower effect), suffering from depression ( $\mathrm{OR}=$ $4.068, \mathrm{CI}=2.551-6.489 ; p<0.001)$, anxiety $(\mathrm{OR}=1.829$, $\mathrm{CI}=1.183-2.827 ; p<0.001)$, and PTSD $(\mathrm{OR}=4.865, \mathrm{CI}=$ 2.616-9.050; $p<0.001)$, and experiencing financial threat $(\mathrm{OR}=1.177, \mathrm{CI}=1.112-1.246 ; p<0.001)$, and economic hardship ( $\mathrm{OR}=1.245, \mathrm{CI}=1.158-1.339 ; p<0.001)$ were the suicidal behavior risk factors. Although depression, anxiety, and PTSD were the suicidal behavior risk factors for Manikganj participants only, financial threat and economic hardship were significant for both Manikganj and Kurigram (Table 4).

\section{Discussion}

The negative consequences of a natural disaster can be extremely destructive to properties and crops, financial conditions, the danger of life, even responsible for unwanted injuries and deaths, etc., which are the most common features of the survivors' mental instabilities. ${ }^{20}$ In the extreme cases, psychological vulnerability may lead them to suicidal behaviors and actual suicide occurrences. ${ }^{35,36}$ However, the present study provides an initial observation of suicidal behaviors among the Bangladeshi flood survivors. Besides, the present findings are anticipated to provide benchmark information, because there is also limited information on suicidal behaviors in global literature. ${ }^{15,36}$

As there is no prior study assessing suicidal behaviors to this cohort in Bangladesh, ${ }^{13,15}$ even no suicide surveillance system or database accumulating any cohort-specific information, ${ }^{37,38}$ hence, the present study suicidal behavior rates' comparison is limited. Nevertheless, the flood survivors' suicidal behavior rates (ie, $57.5 \%$ suicidal ideation, $5.7 \%$ suicide plan and $2.0 \%$ suicide attempt) can be compared with the Bangladeshi general people suicidality. For instance, $13.8 \%$ to $14.7 \%$ and $61.1 \%$ of university students reported past-year and lifetime suicidal thoughts respectively, ${ }^{31,39}$ whereas it was $5 \%$ for adolescent's lifetime ideation. ${ }^{40}$ Besides, another review paper claimed suicidal ideation was $14 \%$ among pregnant women, $11-21 \%$ among ever-married women, and $28 \%$ among abused women. ${ }^{41}$ Although the review did not provide information on how many times were considered for 
Table 4 Regression Analysis Concerning Suicidal Behavior Across the Study Site

\begin{tabular}{|c|c|c|c|c|c|c|}
\hline \multirow[t]{2}{*}{ Variables } & \multicolumn{2}{|l|}{ Total Sample } & \multicolumn{2}{|l|}{ Manikganj } & \multicolumn{2}{|l|}{ Kurigram } \\
\hline & OR; $95 \% \mathrm{Cl}$ & $p$-value & OR; $95 \% \mathrm{Cl}$ & $p$-value & OR; 95\% Cl & p-value \\
\hline \multicolumn{7}{|c|}{ Socio-demographic variables } \\
\hline \multicolumn{7}{|l|}{ Gender } \\
\hline Female & $0.823(0.537-1.259)$ & \multirow[t]{2}{*}{0.368} & I.I $70(0.932-3.362)$ & \multirow[t]{2}{*}{0.081} & $0.623(0.265-1.464)$ & \multirow[t]{2}{*}{0.278} \\
\hline Male & Reference & & Reference & & Reference & \\
\hline \multicolumn{7}{|l|}{ Family status } \\
\hline Lower class & $2.055(1.020-4.141)$ & \multirow[t]{2}{*}{0.044} & $1.385(0.5 \mathrm{I} 2-3.742)$ & \multirow[t]{2}{*}{0.521} & $3.556(1.081-11.693)$ & \multirow[t]{2}{*}{0.037} \\
\hline Middle class & Reference & & Reference & & Reference & \\
\hline \multicolumn{7}{|c|}{ Having number of total children } \\
\hline I to 4 & $0.786(0.406-1.519)$ & \multirow[t]{2}{*}{0.473} & $2.977(0.638-13.881)$ & \multirow[t]{2}{*}{0.165} & $1.120(0.384-3.270)$ & \multirow[t]{2}{*}{0.836} \\
\hline More than 4 & Reference & & Reference & & Reference & \\
\hline \multicolumn{7}{|c|}{ Educational status } \\
\hline No education & $3.390(1.654-6.948)$ & \multirow[t]{3}{*}{0.004} & $1.829(0.688-4.857)$ & \multirow[t]{3}{*}{0.381} & $3.102(0.801-12.017)$ & \multirow[t]{3}{*}{0.123} \\
\hline Primary & $2.867(1.394-5.897)$ & & $1.941(0.748-5.036)$ & & $4.57 \mid(1.064-19.650)$ & \\
\hline Secondary & Reference & & Reference & & Reference & \\
\hline \multicolumn{7}{|c|}{ Having number of earning members in the family } \\
\hline None & $2.556(0.859-7.605)$ & \multirow[t]{3}{*}{0.006} & $1.025(0.180-5.832)$ & \multirow[t]{3}{*}{0.573} & $2.647(0.267-26.245)$ & \multirow[t]{3}{*}{0.546} \\
\hline One & $2.265(1.354-3.789)$ & & 1.431 (0.7I9-2.847) & & $1.749(0.577-5.304)$ & \\
\hline More than one & Reference & & Reference & & Reference & \\
\hline \multicolumn{7}{|c|}{ Got any flood warning } \\
\hline No & $1.290(0.828-2.010)$ & \multirow[t]{2}{*}{0.260} & $1.738(0.932-3.239)$ & \multirow[t]{2}{*}{0.082} & $1.743(0.653-4.654)$ & \multirow[t]{2}{*}{0.267} \\
\hline Yes & Reference & & Reference & & Reference & \\
\hline Preventive me & ken & & & & & \\
\hline No & $0.765(0.492-1.190)$ & 0.236 & $1.345(0.726-2.492)$ & 0.346 & $1.099(0.405-2.981)$ & 0.853 \\
\hline Yes & Reference & & Reference & & Reference & \\
\hline Effects of flood & & & & & & \\
\hline Severe effect & $7.096(3.205-15.710)$ & $<0.001$ & $2.07 \mid(0.798-5.377)$ & 0.321 & & \\
\hline Moderate effect & 3.021 (1.374-6.644) & & $1.660(0.706-3.902)$ & & & \\
\hline Lower effect & Reference & & Reference & & & \\
\hline Depression & & & & & & \\
\hline Yes & $4.068(2.55 I-6.489)$ & $<0.001$ & $3.418(1.760-6.639)$ & $<0.001$ & $2.045(0.797-5.248)$ & 0.137 \\
\hline No & Reference & & Reference & & Reference & \\
\hline
\end{tabular}

(Continued) 
Table 4 (Continued).

\begin{tabular}{|c|c|c|c|c|c|c|}
\hline \multirow[t]{2}{*}{ Variables } & \multicolumn{2}{|l|}{ Total Sample } & \multicolumn{2}{|l|}{ Manikganj } & \multicolumn{2}{|l|}{ Kurigram } \\
\hline & OR; $95 \% \mathrm{Cl}$ & $p$-value & OR; 95\% Cl & $p$-value & OR; 95\% Cl & $p$-value \\
\hline \multicolumn{7}{|l|}{ Anxiety } \\
\hline Yes & $1.829(1.183-2.827)$ & \multirow[t]{2}{*}{0.007} & $2.226(1.186-4.177)$ & \multirow[t]{2}{*}{0.013} & $0.797(0.338-1.878)$ & \multirow[t]{2}{*}{0.604} \\
\hline No & Reference & & Reference & & Reference & \\
\hline \multicolumn{7}{|l|}{ PTSD } \\
\hline Yes & $4.865(2.616-9.050)$ & \multirow[t]{2}{*}{$<0.001$} & $5.600(2.084-|5.05|)$ & \multirow[t]{2}{*}{$<0.001$} & $1.587(0.410-6.148)$ & \multirow[t]{2}{*}{0.504} \\
\hline No & Reference & & Reference & & Reference & \\
\hline Age & $1.000(0.986-1.015)$ & 0.952 & $1.003(0.982-1.025)$ & 0.759 & $1.007(0.979-1.036)$ & 0.632 \\
\hline Financial threat & I.I77 (1.II2-1.246) & $<0.001$ & $1.190(1.084-1.307)$ & $<0.001$ & $1.193(1.06 I-1.34 I)$ & 0.003 \\
\hline Economic hardship & $1.245(I .158-1.339)$ & $<0.001$ & $1.236(1.106-1.383)$ & $<0.001$ & I.197 (I.06I-I.350) & 0.003 \\
\hline
\end{tabular}

assessing suicidal ideation, ${ }^{41}$ which may limit direct comparison with the present findings. However, the present study considered approximately $4 / 5$-month suicidal behavior rates, which alludes to the cohort is highly suicide prone based on the previously available Bangladeshi statistics.

In Australia, a recent study observing 6 months after the 2017 flooding reported that $7 \%$ of the survivors were suicide ideators. ${ }^{42} \mathrm{~A}$ similar rate was reported, that is $10.6 \%$ after the 1 -month of 2008 earthquake, ${ }^{43}$ which decreased over time to $9.06 \%$ after eight years of that earthquake in China. ${ }^{35}$ Besides, a $6.13 \%$ prevalence rate was suggested after 15-16 months of the 2010 earthquake in Haiti ${ }^{44} 9.8 \%$ after 3 years of a 2011 earthquake in Japan, ${ }^{45}$ etc. However, some of the studies claimed relatively higher rates; for instance, the rate was increased to $16.8 \%$ after 2 months of the earthquake in Turkey, ${ }^{19} 20 \%$ after 10 months of Hurricane in the USA, ${ }^{46} 38 \%$ after 12 months of Cyclone in India, ${ }^{47}$ etc. Considering the global natural disaster-related suicidal ideation rates, ${ }^{15}$ the present cohort can be undoubtedly concluded as the most vulnerable cohort ever reported in the literature.

It's evident that survivors' life quality proportionally ups-and-downs with the severity of flood consequences. A waned tendency in mental health sufferings is observed over time of the flood exposure, based on a 2-year UK longitudinal study. ${ }^{48}$ That emphasis, the more time gets, the less effect of the trauma is persisted; this may be because of rising resilience and higher ability to cope with stressors among the survivors. Similarly, survivors with fewer flood effects are less vulnerable to mental sufferings. $^{2}$ As aforementioned, Kurigram within two study sites was reported to be more affected by the flood, ${ }^{16,17}$ which was also found in the present participants' responses (see Supplementary Table S1). For instance, $84.1 \%$ of the respondents became unemployed in Kurigram, which was much higher than Manikganj. Similarly, other effects such as having damaged crops and houses, losing domestic animals, being physically injured, experiencing more family member deaths, etc., were reported highly in Kurigram, and they also did not get enough relief for combating their greater losses. These effects lead to more psychological burdens to the survivors as reported in the previous literature. For instance, a study considering 3,609 survivors of the 1999 Marmara Earthquake, Turkey observed that suicidal thought risk increased 1.76-time higher among these who experienced a severe injury of themselves or their relatives, the risk was 1.57 and 1.35 times higher for losing their relatives and having extensive damage or destruction occurred in their home or property, respectively. ${ }^{19}$ Therefore, reporting more psychological effects among the participants belonging to more flood-affected regions (ie, Kurigram compared to Manikganj) is not unsual. Thus, $84.8 \%$ of suicidal ideation was reported in Kurigram, which was only $33.2 \%$ for the Manikganj participants. However, there were no significant differences in suicide plans and suicide attempts between the two study sites, which is not well explainable to the author's best knowledge. Although 
a significant portion of the flood survivors thought to commit suicide, family and social responsibilities might resist them to take the forward decisions; thus, suicide plan and suicide attempt rates were lower and insignificant across two study sites.

A flood is a disastrous event that is most likely considered for PTSD mediators, following by other sufferings such as depression, anxiety, hopelessness, adjustment disorder, etc. ${ }^{36}$ As aforementioned, these psychological instabilities are commonly blamed for actual suicide completion. A previous Bangladeshi study observed that the common mental disorders in $90 \%$ of the suicidal patients. ${ }^{49}$ Hence, flood survivors suffering from higher levels of mental disorders along with socio-economic effects like higher economic loss, are prone to suicide, which was conceptually mapped in a recent review article. $^{36}$ The present study also reechoed analogously ascertains concerning suicidal thought and mental health sufferings. For example, participants with PTSD were at risk of being five times higher suicidal ideators, whereas depression and anxiety accounted for four- and two-time risk, respectively. Similarly, a Chinese study among 1,369 participants after eight years of an earthquake occurrence reported that PTSD increased two times higher suicidality risk, whereas more than 4 times risk was reported for depression. $^{35}$

\section{Conclusions}

Floods have a subsequent impact on humanity affecting their resources and properties irreplaceably. Thus, not surprisingly, the flood survivors have to suffer from elevated psychological problems including suicidal behaviors. As Bangladesh is geographically prone to natural disasters, there is limited scope to escape from these deleterious events. However, a proper policy and its effective implementation by the operation of government, NGOs, locals, etc., can help alleviate the frequent flood impacts. ${ }^{50}$ Based on the present findings, special attention in respect to the mental health aspects and harm reducing privileges are warranted to these people who are affected by the flood severely, and the people with mental disorders should also be considered in the priority list. Besides, considering the present study limitations (most importantly, cross-sectional study), further longitudinal studies assessing the actual mental health causalities can be helpful to such programs.

\section{Acknowledgments}

The authors would like to thank all the participants, and data collectors involved in the project (most importantly, A.K.M. Israfil Bhuiyan, Rafia Tasnim, Naim Pramanik, Abu Bakkar Siddique, Abu Hasnat Abdullah and Md. Abedin Sarker). Besides, we would like to acknowledge that the project was run by the Undergraduate Research Organization, presently which will be introduced as the Centre for Health Innovation, Networking, Training, Action and Research - Bangladesh (CHINTA Research Bangladesh).

\section{Funding}

There is no funding to report.

\section{Disclosure}

The authors involved in this research communication do not have any relationships with other people or organizations that could inappropriately influence (bias) the findings. The authors of the paper do not have any conflicts of interest.

\section{References}

1. Karim MF, Mimura N. Impacts of climate change and sea-level rise on cyclonic storm surge floods in Bangladesh. Glob Environ Change. 2008;18(3):490-500. doi:10.1016/j.gloenvcha.2008.05.002

2. Mamun MA, Huq N, Papia ZF, Tasfina S, Gozal D. Prevalence of depression among Bangladeshi village women subsequent to a natural disaster: a pilot study. Psychiatry Res. 2019;276:124-128. doi:10.1016/j.psychres.2019.05.007

3. Ahmed HU, Alam MT, Hossain T, Rabbani MG, Alam MWA. Mental health service after disaster: Bangladesh perspective. Eur Psychiatry. 2015;30(S1):1. doi:10.1016/S0924-9338(15)32123-4

4. Concern Worldwide US. Floods in Bangladesh cause devastation. 2019. Available from: https://www.concernusa.org/story/floodsbangladesh/. Accessed September 5, 2020.

5. Flood List. Bangladesh - 167,000 families still displaced by floods says UN. 2020. Available from: https://bit.ly/3byEPzp. Accessed September 5, 2020.

6. Fernandez A, Black J, Jones M, et al. Flooding and mental health: a systematic mapping review. PLoS One. 2015;10(4):e0119929. doi:10.1371/journal.pone.0119929

7. Shahnaz A, Bagley C, Simkhada P, Kadri S. Suicidal behaviour in Bangladesh: a scoping literature review and a proposed public health prevention model. Open J Soc Sci. 2017;5(7):254-282.

8. Mamun MA, Akter S, Hossain I, et al. Financial threat, hardship and distress predict depression, anxiety and stress among the unemployed youths: a Bangladeshi multi-city study. $J$ Affect Disord. 2020;276:1149-1158. doi:10.1016/j.jad.2020.06.075

9. Rafi MA, Mamun MA, Hsan K, Hossain M, Gozal D. Psychological implications of unemployment among Bangladesh civil service job seekers: a pilot study. Front Psychiatry. 2019;10:e578.

10. Mamun MA, Ullah I. COVID-19 suicides in Pakistan, dying off not COVID-19 fear but poverty? - The forthcoming economic challenges for a developing country. Brain Behav Immun. 2020;87:163-166. doi:10.1016/j.bbi.2020.05.028 
11. Mamun MA, Griffiths MD. A rare case of Bangladeshi student suicide by gunshot due to unusual multiple causalities. Asian J Psychiatr. 2020;49:e101951. doi:10.1016/j.ajp.2020.101951

12. Hossain MD, Ahmed HU, Chowdhury WA, Niessen LW, Alam DS. Mental disorders in Bangladesh: a systematic review. $B M C$ Psychiatry. 2014;14(1):e8. doi:10.1186/s12888-014-0216-9

13. Nahar N, Blomstedt Y, Wu B, Kandarina I, Trisnantoro L, Kinsman J. Increasing the provision of mental health care for vulnerable, disaster-affected people in Bangladesh. BMC Public Health. 2014;14(1):e708. doi:10.1186/1471-2458-14-708

14. Mamun MA, Siddique AB, Sikder MT, Griffiths MD. Student suicide risk and gender: a retrospective study from Bangladeshi press reports. Int J Ment Health Addict. 2020. doi:10.1007/s11469-020-00267-3

15. Kõlves K, Kõlves KE, De Leo D. Natural disasters and suicidal behaviours: a systematic literature review. $J$ Affect Disord. 2013;146(1):1-14. doi:10.1016/j.jad.2012.07.037

16. The Daily Star. Flood situation worsens in Manikganj. 2019. Available from: https://www.thedailystar.net/country/news/floodsituation-worsens-manikganj-1774291. Accessed September 5, 2020.

17. The Daily Star. Flood situation worsens in Kurigram, improves in Lalmonirhat. 2019. Available from: https://www.thedailystar.net/ban gladesh-flood-situation-worsens-in-lalmonirhat-and-kurigram -1929069. Accessed September 5, 2020.

18. Disu TR, Anne NJ, Griffiths MD, Mamun MA. Risk factors of geriatric depression among elderly Bangladeshi people: a pilot interview study. Asian J Psychiatr. 2019;44:163-169. doi:10.1016/j.ajp.2019.07.050

19. Vehid HE, Alyanak B, Eksi A. Suicide ideation after the 1999 earthquake in Marmara, Turkey. Tohoku J Exp Med. 2006;208(1):19-24. doi:10.1620/tjem.208.19

20. Dai W, Kaminga AC, Tan H, et al. Long-term psychological outcomes of flood survivors of hard-hit areas of the 1998 Dongting Lake flood in China: prevalence and risk factors. PLoS One. 2017;12(2): e0171557. doi: 10.1371 /journal.pone. 0171557

21. Kroenke K, Spitzer RL, Williams JBW. The PHQ-9: validity of a brief depression severity measure. J Gen Intern Med. 2001;16 (9):606-613. doi:10.1046/j.1525-1497.2001.016009606.x

22. Mamun MA, Griffiths MD. The association between Facebook addiction and depression: a pilot survey study among Bangladeshi students. Psychiatry Res. 2019;271:628-633. doi:10.1016/j.psychres.2018.12.039

23. Spitzer RL, Kroenke K, Williams JBW, Löwe B. A brief measure for assessing generalized anxiety disorder: the GAD-7. Arch Intern Med. 2006;166(10):1092-1097. doi:10.1001/archinte.166.10.1092

24. Bhuiyan MAH, Griffiths MD, Mamun MA. Depression literacy among Bangladeshi pre-university students: differences based on gender, educational attainment, depression, and anxiety. Asian J Psychiatr. 2020;50:e101944. doi:10.1016/j.ajp.2020.101944

25. Brewin CR, Rose S, Andrews B, et al. Brief screening instrument for post-traumatic stress disorder. Br J Psychiatry. 2002;181(2):158-162. doi:10.1192/bjp.181.2.158

26. Dekkers AMM, Olff M, Näring GWB. Identifying persons at risk for PTSD after trauma with TSQ in the Netherlands. Community Ment Health J. 2010;46(1):20-25. doi:10.1007/s10597-009-9195-6

27. Marjanovic Z, Greenglass ER, Fiksenbaum L, Bell CM. Psychometric evaluation of the Financial Threat Scale (FTS) in the context of the great recession. J Econ Psychol. 2013;36:1-10. doi:10.1016/j.joep.2013.02.005

28. Jesus SN, Leal AR, Viseu JN, et al. Coping as a moderator of the influence of economic stressors on psychological health. Analise Psicologica. 2016;34(4):365-376. doi:10.14417/ap.1122

29. Lempers JD, Clark-Lempers D, Simons RL. Economic hardship, parenting, and distress in adolescence. Child Dev. 1989;60:25-39. doi: $10.2307 / 1131068$

30. Jahan S, Araf K, Gozal D, Griffiths MD, Mamun MA. Depression and suicidal behaviors among Bangladeshi mothers of children with autism spectrum disorder: a comparative study. Asian J Psychiatr. 2020;51:e101994. doi:10.1016/j.ajp.2020.101994
31. Mamun MA, Rayhan I, Akter K, Griffiths M. Prevalence and predisposing factors of suicidal ideation among the university students in Bangladesh: a single-site survey. Int J Ment Health Addict. 2020. doi:10.1007/s11469-020-00403-z

32. McKinnon B, Gariépy G, Sentenac M, Elgar FJ. Adolescent suicidal behaviours in 32 low-and middle-income countries. Bull World Health Organ. 2016;94(5):340-350F. doi:10.2471/BLT.15.163295

33. Peltzer K, Yi S, Pengpid S. Suicidal behaviors and associated factors among university students in six countries in the Association of Southeast Asian Nations (ASEAN). Asian $J$ Psychiatr. 2017;26:32-38. doi:10.1016/j.ajp.2017.01.019

34. Asante KO, Kugbey N, Osafo J, Quarshie EN-B, Sarfo JO. The prevalence and correlates of suicidal behaviours (ideation, plan and attempt) among adolescents in senior high schools in Ghana. SSM Popul Health. 2017;3:427-434. doi:10.1016/j.ssmph.2017.05.005

35. Guo J, Liu C, Kong D, Solomon P, Fu M. The relationship between PTSD and suicidality among Wenchuan earthquake survivors: the role of PTG and social support. $J$ Affect Disord. 2018;235:90-95. doi:10.1016/j.jad.2018.04.030

36. Zhong S, Yang L, Toloo S, et al. The long-term physical and psychological health impacts of flooding: a systematic mapping. Sci Total Environ. 2018;626:165-194. doi:10.1016/j.scitotenv.2018.01.041

37. Mamun MA, Griffiths MD. Mandatory junior school certificate exams and young teenage suicides in Bangladesh: a response to arafat (2020). Int J Ment Health Addict. 2020. doi:10.1007/s11469-020-00324-x

38. Mamun MA, Griffiths MD. Young teenage suicides in Bangladeshare mandatory junior school certificate exams to blame? Int $J$ Ment Health Addict. 2020. doi:10.1007/s11469-020-00275-3

39. Rahman ME, Islam M, Mamun MA, Moonajilin MS, Yi S. Prevalence and factors associated with suicidal ideation among university students in Bangladesh. Arch Suicide Res. 2020;1-10. doi:10.1080/13811118.2020.1833800

40. Begum A, Rahman AKMF, Rahman A, Soares J, Reza Khankeh H, Macassa G. Prevalence of suicide ideation among adolescents and young adults in rural Bangladesh. Int J Ment Health. 2017;46 (3):177-187. doi:10.1080/00207411.2017.1304074

41. Newman MS. Review of studies of mental health in Bangladesh, with a focus on depression. Int $J$ Ment Health. 2013;42(4):48-77. doi:10.2753/IMH0020-7411420403

42. Matthews V, Longman J, Berry HL, et al. Differential mental health impact six months after extensive river flooding in rural Australia: a cross-sectional analysis through an equity lens. Front Public Health. 2019;7:e367. doi:10.3389/fpubh.2019.00367

43. Yu X, Lau JTF, Zhang J, et al. Posttraumatic growth and reduced suicidal ideation among adolescents at month 1 after the Sichuan Earthquake. J Affect Disord. 2010;123(1-3):327-331. doi:10.1016/j. jad.2009.09.019

44. Wagenaar BH, Hagaman AK, Kaiser BN, McLean KE, Kohrt BA. Depression, suicidal ideation, and associated factors: a cross-sectional study in rural Haiti. BMC Psychiatry. 2012;12(1): e149. doi:10.1186/1471-244X-12-149

45. Morishima R, Ando S, Araki T, et al. The course of chronic and delayed onset of mental illness and the risk for suicidal ideation after the Great East Japan Earthquake of 2011: a community-based longitudinal study. Psychiatry Res. 2019;273:171-177. doi:10.1016/j. psychres.2018.12.151

46. Larrance R, Anastario M, Lawry L. Health status among internally displaced persons in Louisiana and Mississippi travel trailer parks. Ann Emerg Med. 2007;49(5):590-601. doi:10.1016/j. annemergmed.2006.12.004

47. Kar N. Suicidality following a natural disaster. Am J Disaster Med. 2010;5(6):361-368. doi:10.5055/ajdm.2010.0042

48. Jermacane D, Waite TD, Beck CR, et al. The English National Cohort Study of flooding and health: the change in the prevalence of psychological morbidity at year two. BMC Public Health. 2018;18(1): e330. doi:10.1186/s12889-018-5236-9 
49. Shah MMA, Sajib MWH, Arafat SMY. Demography and risk factor of suicidal behavior in Bangladesh: a cross-sectional observation from patients attending a suicide prevention clinic of Bangladesh. Asian J Psychiatr. 2018;35:4-5. doi:10.1016/j.ajp.2018.04.035
50. Dewan TH. Societal impacts and vulnerability to floods in Bangladesh and Nepal. Weather Clim Extrem. 2015;7:36-42. doi:10.1016/j.wace.2014.11.001

\section{Publish your work in this journal}

Risk Management and Healthcare Policy is an international, peerreviewed, open access journal focusing on all aspects of public health, policy, and preventative measures to promote good health and improve morbidity and mortality in the population. The journal welcomes submitted papers covering original research, basic science, clinical \& epidemiological studies, reviews and evaluations, guidelines, expert opinion and commentary, case reports and extended reports. The manuscript management system is completely online and includes a very quick and fair peer-review system, which is all easy to use. Visit http://www.dovepress.com/testimonials.php to read real quotes from published authors. 